\title{
TOXOPLASMOSE EM PRIMATAS NÃO HUMANOS. II - Tentativas de infecções experimentais em Macacca mulatta, Cebus apella e Callithrix jacchus; e pesquisa de anticorpos em várias espécies de platyrrhinus ${ }^{1 *}$
}

\section{F. NERY-GUIMARAES $*$ e ANA JANSEN FRANKEN $* * *$}

Instituto Oswaldo Cruz, Rio de Janeiro, Guanabara

(Com 4 estampas)

Em trabalho anterior (12) foi descrita toxoplasmose espontânea em um Macacca mulatta e um Cebus apella. Foi destacada a baixa frequiência da infecção natural nos primatas não humanos; assim como o fato dos casos relatados se referirem a animais mantidos em cativeiro.

Neste trabalho, após uma revisão da toxoplasmose experimental nos símios, são apresentadas as tentativas de infecção experimental em dois catarrinos ( $M$. mulatta) e dois platirrinos (C. apella e Callitbrix jaccbus).

Foi confirmada a grande resistência dos catarrinos ao Toxoplasma. Essa resistência é muito menor nos platirrinos e entre êstes, parece não existir nos grupos mais inferiores e nos Prosimii $(10,18,24,26)$. Por outro lado, a raridade da infecção natural também nos platirrinos foi apoiada pela sorologia, uma vez que de 54 símios do Nôvo Mundo de 5 gêneros diferentes submetidos à reação de Sabin-Feldman, apenas um Saimiri sciureus se mostrou positivo a 1:16 (1,8\%).

Infeç̧ões experimentais de primatas não humanos por Toxoplasma. Já em 1909, quando da descoberta do parasito, Nicolle \& Manceaux inocularam 2 Macacus cynomolgus (= Macacca irus?) um no peritôneo e outro sob a pele, com resultados negativos. Ainda com material de gondi, em 1913, Nicolle \& Conor, inocularam no peritôneo um $M$. cynomolgus e um $M$. sinicus ( $=M$. sinica) e também não tiveram sucesso. Em 1929, Levaditi \& al, com emulsão de cérebro de coelho, inocularam pela via cerebral, 3 macacos: Cercopithecus patas (=Erythrocebus patas), M. mulatta e

\footnotetext{
1 Recebido para publicação a 30 de dezembro de 1970.

* Trabalho do Instituto Oswaldo Cruz (IOC).

* Chefe da Seção de Protozoologia do IOC; Chefe de Pesquisas do Conselho Nacional de Pesquisas; do Quadro de Peritos da Organização Mundial de Saúde.

*** Médico-Veterinário do Instituto Estadual de Medicina Veterinária, Gb.
} 
Papio sphinx (= Mandrillus spbinx), e os resultados foram negativos. Em 1931, Bland inoculou vários $M$. mulatta com toxoplasmas de coelho, obtendo os primeiros resultados parcialmente positivos : os animais apresentaram febre e poliadenia, mas se recuperaram. Levaditi \& Schoen, em 1933, com emulsão de cérebro de coelho, inocularam por via cerebral um Cynocephalus bubuin (=Papio cynocephalus?), com resultados negativos. Em 1937, Sabin \& Olitsky, pela via cerebral, produziram infecção febril, não fatal, em M. mulatta; e no mesmo animal pela via subcutânea, observaram lesão local e depois infecção sistêmica, isolando os parasitos em camundongos inoculados com o sangue dos macacos. Todos os rhesus se recuperaram e mostraram anticorpos neutralizantes no sôro. Em 1940, Wolf \& al inocularam 2 rhesus com amostras humanas com resultados negativos, usando conjuntamente as vias cerebral, venosa e subcutânea. Em 1941, Sabin infectou 4 rbesus por via cerebral com doses maciças, de 2 amostras humanas (inclusive a $\mathrm{RH}$ ). Os animais tiveram infecção aguda e mortal com lesões e parasitos nos principais órgãos. Outros 4 rbesus inoculados por outras vias sobreviveram. Ainda em rhesus, resultados parcialmente positivos foram obtidos por Sabin \& Ruchman em 1942, usando além da via subcutânea, a peritoneal; os animais tiveram febre, mas se recuperaram, mostrando anticorpos neutralizantes no sôro. Em 1945, Cowen \& Wolf obtiveram infecção fatal em um rhesus infante. Na mesma ocasião infectaram outros rbesus, que se recuperaram, mostrando anticorpos neutralizantes no sôro; ao passo que um Cercopithecus sabaeus ( $=C$. aethiops sabaeus) e um Papio doguera, foram negativos. Nove anos depois, Enid de Rodaniche (1954), com toxoplasmas isolados de Cebus capucinus, provocou infecção aguda e fatal, por várias vias, em 26 Marikina geoffroyi, de 28 inoculados, e em 11 Aotus zonalis, de 15 inoculados. Em 1955, Mohr \& al, usando várias vias e inóculos elevados, produziram infecções graves em 7 rhesus, de 8 inoculados, com morte de 6 animais. Weinman \& Chandler (1956) infectaram 2 rbesus, alimentando-os com tecidos contaminados. Os animais desenvolveram anticorpos na faixa significativa de 1:64 a 1:16384, respectivamente. Em 1957 Makstenieks \& Verlinde inocularam 4 rbesus (subcutânea), e 4 cynomolgus ( $M$. irus?) através de escarificações cutâneas. Não houve doença, mas foi comprovada parasitemia por inoculação em camundongo. Os macacos foram sacrificados 12-18 meses depois e foi isolado toxoplasma do SNC e dos gânglios linfáticos. A RSF e RFC tornaram-se positivas até 1:256 e 1:32, respectivamente. Um rhesus e um cynomolgus, inoculados por via oral, tiveram reações negativas e não mostraram anticorpos circulantes. Esses mesmos autores fizeram tentativas para provocar infecções congênitas em 
2 cynomolgus grávidas, mas falharam. Sureau \& al, em 1962, com amostra de toxoplasmas isolada de Lemur catta, produziram infecção fatal em 3 lemures normais. Finalmente, em 1969, Werner \& al, usando as vias peritoneal e oral e inóculos com dezenas de milhões e centenas de milhões de toxoplasmas, produziram infecções fatais em 28 Saguinus Oedipomidas oedipus. O quadro 1 mostra êsses dados em sinópse, já incluídos os macacos usados nas experiências dêste trabalho.

QUADRO I

INFECÇŌES EXPERIMENTAIS EM PRIMATAS NAO HUMANOS $(1909-1971)$

PROSIMII - Lemur catta - Sureau, $1962(+)$

PLATYRRHINUS - Marikina geoffroyi - Rodaniche, $1954(+)$

Aotus zonalis - Rodaniche, 1954 (+)

Callithrix jacchus - Nery-Guimarães \& Jansen Franken, $1971(+)$

Saguinus Oedipomidas oedipus - Werner \& al, $1969(+)$

Cebus apella - Nery-Guimarães \& Jansen Franken, (1971 ( \pm )

CATHARRHINUS - Macacca irus - Nicolle \& Manceaux, 1909 (-)

Nicolle \& Conor, $1913(-)$

Makstenieks \& Verlinde, $1967( \pm)$

Macacca mulatta - Levaditi \& al, 1957 (-)

Bland, $1931( \pm)$

Sabin \& Olitsky, $1937( \pm)$

Sabin, $1941(+)$

Wolf, Cowen \& Paige, 1940 (-)

Sabin \& Ruchman, $1942( \pm)$

Cowen \& Wolf, $1945(+)$

Mohr \& al, 1955 (+)

Weidman \& Chandler, $1956(-)$

Makstenieks \& Verlinde, $1957(+)$

Nery-Guimarães \& Jansen Franken, 1971 (一)

Macacca sinica - Nicolle \& Conor, 1913 (-)

Cercopithecus patas (=Erythrocebus patas)

Levaditi \& al, $1929(-)$

Cercopithecus sabaeus $(=C$. aethiops sabaeus)

Cowen \& Wolf, $1945(-)$

Papio sphinx - Levaditi \& al, 1929 (-)

Papio cynocephalus - Levaditi \& Schoen, 1933 (-)

Papio doguera - Cowen \& Wolf, 1945 (-)

$(-)=$ Negativo $(+)=$ Positivo $( \pm)=$ Infecção leve ou não fatal 
Mem. Inst. Oswaldo Cruz, 69 (2), 1971

\section{EXPERIENCIAS E RESULTADOS}

A - Tentativas de infecção de primatas não bumanos. Foi usada uma amostra humana isolada de toxoplasmose congênita. $O$ inóculo foi 1 a $3 \mathrm{ml}$ de suspensão de cérebro e líquido peritoneal de camundongos infectados.

Catarrinos. Foram usados 2 rbesus (Macacca mulatta): uma fêmea jovem de 16 meses e um macho infante de 6 meses. Foram feitas inoculações e reinoculações na seguinte ordem: peritoneal, subcutânea, oral (só a fêmea) cerebral, pleural, endovenosa (só a fêmea) e novamente pleural (só a fêmea).

Rhesus fêmea. Nos 2 ou 3 dias seguintes a cada injeção, o animal mostrava-se geralmente triste, às vêzes até rejeitando os alimentos e apresentava também elevação de temperatura $\left(39^{\circ}\right.$ a $\left.41,5^{\circ} \mathrm{C}\right)$, mas depois se recuperava. Depois da $1 .^{a}$ inoculação pleural passou a receber decametasona $2 \mathrm{mg} / 10$ vêzes/12 dias. Estêve magra, mas recuperou o pêso. Aos 30 dias do início da experiência a reação de Sabin-Feldman (RSF) foi positiva $(1: 256)$. Inoculação do seu sangue em camundondos aos 10 dias e aos 66 dias de experiência, foi negativa. Foi sacrificada aos 3 meses de experiência. Nesse dia a RSF foi positiva 1:64. Com suspensão de cérebro foram inoculados camundongos com resultado negativo. Na autópsia não foram encontradas lesões macroscópicas. Nos cortes das vísceras não foram encontrados toxoplasmas.

Rhesus infante. $O$ animal se manteve sempre ativo depois de cada injeção. Só teve febre $\left(40,3^{\circ} \mathrm{C}\right)$ depois da inoculação pleural. Teve diarréia, porém, esta foi atribuída a enteroprotozoa (Balantidium e Entamoeba). Aos 28 dias do início da experiência a RSF foi positiva 1:64. Aos 30 dias passou a receber decametasona $(1 \mathrm{mg} / 8$ vêzes $/ 10$ dias). Ficou magro; teve febre (até $41^{\circ} \mathrm{C}$ ). Foi sacrificado com 35 dias de experiência. Na autópsia não foram vistas lesões macroscópicas. Impressões de baço, fígado e pulmões negativas. Também não foram encontrados toxoplasmas nos cortes das principais vísceras. No fígado foram vistos pequenos acúmulos de células redondas esparsos no parênquima. A pesquisa exaustiva de cistos toxoplásmicos no encéfalo foi negativa. No pulmão foi visto foco inflamatório periférico discreto, provàvelmente relacionado com a inoculação pleural. No coração támbém foram vistos raros acúmulos de células inflamatórias, também sem parasitos. A inoculação de suspensão de cérebro em camundongos (sempre grupos de 4 animais) também foi negativa. 
Nery-Guimarães \& Franken: Toxoplasmose em primatas II 101

\section{QUADRO 2}

RESULTADOS DA REAÇAO DE SABIN-FELDMAN EM SOROS DE 54 SIMIOS DO NOVO MUNDO. 40 COLHIDOS PELO INSTITUTO EVANDRO CHAGAS (ESTADO DO PARA) E 14 COLHIDOS NO JARDIM ZOOLOGICO DO ESTADO DA GUANABARA.

\begin{tabular}{|c|c|c|c|c|c|}
\hline \multicolumn{2}{|c|}{ SIMIOS } & \multirow{2}{*}{$\begin{array}{l}\text { N.o de } \\
\text { exem- } \\
\text { plares }\end{array}$} & \multicolumn{2}{|c|}{ Positivos } & \multirow{2}{*}{ Negativos } \\
\hline Classificação & Nome popular & & $1: 4$ & $1: 16$ & \\
\hline $\begin{array}{l}\text { Saimiri sciureus } \\
\text { Cebus apella } \\
\text { Alouatta belzeboul } \\
\text { Aotus sp } \\
\text { Callithrix geoffroyi } \\
\text { C. jacchus } \\
\text { C. penicillata } \\
\text { Cebus apella } \\
\text { Lagothrix lagothrica }\end{array}$ & $\begin{array}{l}\text { "Macaco de Chelro" } \\
\text { "Macaco prego" } \\
\text { "Guariba" } \\
\text { "Macaco da nolte" } \\
\text { "Mico da cara } \\
\text { branca" } \\
\text { "Mico estrêla" } \\
\text { "Mico estrêla" } \\
\text { "Macaco prego" } \\
\text { "Macaco barrigudo" }\end{array}$ & $\begin{array}{r}17 \\
22 \\
1 \\
1 \\
1 \\
1 \\
2 \\
5 \\
4 \\
1\end{array}$ & $\begin{array}{l}2 \\
4 \\
- \\
- \\
- \\
- \\
- \\
-\end{array}$ & $\begin{array}{l}1 \\
- \\
- \\
- \\
- \\
-\end{array}$ & $\begin{array}{r}14 \\
18 \\
1 \\
1 \\
\\
1 \\
2 \\
5 \\
4 \\
1\end{array}$ \\
\hline Totais & - & 54 & 6 & 1 & 47 \\
\hline
\end{tabular}

QUADRO 3

RESULTADOS DE 26 TENTATIVAS DE INFECÇAO EXPERIMENTAL EM PRIMATAS NAO HUMANOS (1909-1970) - VARIOS AUTORES

\begin{tabular}{|c|c|c|c|c|c|c|}
\hline \multirow{2}{*}{$\begin{array}{c}\text { Primatas } \\
\text { não } \\
\text { humanos }\end{array}$} & \multirow{2}{*}{$\begin{array}{l}\text { N.o de } \\
\text { espécies }\end{array}$} & \multirow{2}{*}{$\begin{array}{l}N^{\circ}{ }^{\circ} \text { de } \\
\text { exem- } \\
\text { plares }\end{array}$} & \multicolumn{2}{|c|}{ Infecções fatais } & \multicolumn{2}{|c|}{ Sobreviventes } \\
\hline & & & espécies & $\begin{array}{l}\text { N. } .^{\circ} \text { de } \\
\text { exem- } \\
\text { plares }\end{array}$ & espécies & $\begin{array}{l}\text { N. }{ }^{\circ} \text { de } \\
\text { exem- } \\
\text { plares }\end{array}$ \\
\hline Prosimii & 1 & 3 & 1 & 3 & 0 & $\mathbf{0}$ \\
\hline Platirrinos & 5 & 73 & 4 & $\begin{array}{c}66 \\
(90,4 \%)\end{array}$ & 1 & 7 \\
\hline Catarrinos & 8 & $65^{*}$ & 1 & $\begin{array}{c}11 \\
(22 \%)\end{array}$ & 7 & 59 \\
\hline Totais & 14 & 141 & 6 & 80 & 8 & 66 \\
\hline
\end{tabular}

(*) Náo fol possivel obter o número exato de rhesus porque alguns autores não deram o número de animais inoculados. 
Platirrinos. Cebus apella, fêmea, adulta. Inoculada no peritôneo com suspensão em salina de órgãos de camundongos infectados. Nos dias seguintes teve febre $\left(39,5-39,9^{\circ} \mathrm{C}\right)$. Oito dias depois foi reinoculada pela via subcutânea; novamente a temperatura subiu até $40,2^{\circ} \mathrm{C}$ a partir do $2 .^{\circ}$ dia. Aos 22 dias, sua RSF foi positiva 1:64. Ao ser reinoculada pela via cerebral apresentou convulsões e morreu horas depois. (Traumatismo cerebral). Na autópsia, não foram vistas lesões macroscópicas. Microscòpicamente, foi encontrado infiltração gorda e acúmulo de células redondas no fígado, ao nível dos EP; discretos focos inflamatórios no miocárdio; e congestão e edema pulmonar. Camundongos inoculados com suspensão de cérebro morreram de toxoplasmose, e êsse resultado foi interpretado como decorrente da presença de parasitos do inóculo; mas, outros 3 camundongos inoculados com material de baço e fígado também foram positivos.

Callitbrix jacchus, macho, inoculado no peritôneo, com suspensão de cérebro de camundongo infectado. $O$ animal no dia seguinte ficou triste e deixou de se alimentar, morrendo aos 4 dias de inoculado. De 4 camundongos inoculado's com suspensão de suas vísceras, 3 morreram em 24 horas e do $4 .^{\circ}$, que sobreviveu por 6 dias, foi isolado toxoplasma por subinoculação. A morte por intercorrência dos 3 camundongos, faz supor que a morte do símio foi apressada por intercorrência bacteriana. Todavia, nos cortes as lesões de baço e do fígado, permitiram o diagnóstico de toxoplasmose aguda. Esses órgãos mostravam focos necróticos esparsos no parênquima, com numerosos parasitos, principalmente no baço. Os toxoplasmas apresentavam-se isolados ou associados sob a forma de pseudocistos. No fígado, os parasitos eram mais abundantes na superfície do órgão e na cápsula de Glisson, onde a necrose era avançada. A impressão era que o órgão estava sendo invadido da periferia para o centro. No coração havia pequenos focos inflamatórios e no cérebro era nítida a proliferação glial, mas nesses órgãos não foram vistos parasitos; e da mesma forma no pulmão, no qual ocorria congestão e edema.

Em resumo. Dois $M$. mulatta (infante e jovem) inoculados e reinoculados com doses maciças de toxoplasmas tiveram quadro febril e sorologia positiva (RSF 1:64 e 1:256, respectivamente), mas se recuperaram, apesar de tratados com decametasona $(1 \mathrm{mg} / 8$ doses/10 dias e $2 \mathrm{mg} 10$ doses/12 dias, respectivamente). A inoculação do seu sangue em camundongos em 2 ou 3 oportunidades, foi negativa, e quando sacrificados 35 e 90 dias, respectivamente, do início das experiências a pesquisa de toxoplasmas em suas vísceras em esfregaços, cortes e inoculações, foi negativa. 
Um C. apella inoculado com doses maciças, teve febre e sorologia positiva (1:64), mas se recuperou. Morreu de acidente ao ser reinoculado pela via cerebral. A pesquisa direta de toxoplasmas em suas vísceras foi negativa; porém, os parasitos foram isolados por inoculação em camundongos.

Um C. jacchus também inoculado no peritôneo com dose maciça, teve infecção sistêmica, com graves lesões necróticas e riqueza de toxoplasmas no baço e no fígado, morrendo aos 4 dias de inoculado.

B - Pesquisa de anticorpos de toxoplasma em simios do Nôvo Mundo

A pesquisa de anticorpos foi feita pela reação de Sabin-Feldman (RSF) com as modificações preconizadas por Frankel \& Jacobs (1958).

Foram pesquisados os sôros de 54 símios, de 8 espécies, em diluições quádruplas. Dos 54 sôros, 40 foram enviados pelo Instituto Evandro Chagas (Belém). E foram colhidos em vários pontos do Estado do Pará e 14 foram de animais sangrados no Jardim Zoológico do Estado da Guanabara.

Dos 54 símios, um exemplar de Saimiri sciureus deu reação 1:64 $(1,8 \%)$ outros 2 Saimiri deram reação 1:4, e 6 Cebus apella deram também reação 1:4. Este título é seguramente sem significação e, portanto, de 54 símios, 53 foram negativos $(98,2 \%)$. Quadro 2 . 


\section{DISCUSSAO}

Os nossos resultados negativos, quanto aos rhesus ( $M$. mulatta) estão de acôrdo com a maioria das experiências realizadas por vários autores neste animal. Por ser o símio comum de laboratório, o rhesus foi o catarrinos mais usado. De 1909 a 1970, foram experimentados cêrca de $50^{*}$ exemplares. Dos outros catarrinos foram experimentados apenas 15, correspondendo a 8 espécies, e todos com resultados negativos. Em apenas 11 rhesus foi obtida infecção fatal (cêrca de $22 \%$ ), pela inoculação de doses maciças e pela via cerebral (isolada ou combinada com outras vias): 4 por Sabin (1941), 1 por Cowen \& Wolf (1945) e 6 por Mohr \& al (1955). Quadro 3. Os resultados de Mohr \& al (1955) são realmente surpreendentes: 6 infecções fatais em 8 rbesus inoculados. Tanto mais quanto os nossos resultados foram negativos, apesar da ministração de doses elevadas de corticosteróides, além da negativa sistemática de outros autores. É verdade que nós usamos uma amostra humana, pouco virulenta; mas, Sabin (1941) também usou amostras humanas.

As nossas tentativas de indução de toxoplasmose fatal nos platirrinos, falharam no $C$. apella, mas tiveram êxito no $C$. jacchus. Vimos que a infecção fatal de platirrinos tem sido obtida com facilidade, principalmente por Rhodaniche (1954) em Marikina e Aotus e por Werner \& al (1969) em Saguinus. Podemos ver no Quadro 3 que, de um total de 73 platirrinos inoculados, 66 tiveram infecção fatal $(90,4 \%)$. Provàvelmente, os platirrinos mais elevados são mais resistentes. Nos Prosimii, Sureau \& al (1962) obtiveram infecção fatal nos 3 L. catta inoculados.

Ruch (1959), citado por McKissick \& al (1968), já chamara a atenção para o fato de que a maioria das infecções por Toxoplasma em primatas não humanos, ocorria em platirrinos. McKissick \& al (1968) verificaram que no Jardim Zoológico de Filadélfia, em 16 anos foi observada toxoplasmose espontânea e fatal em 9 platirrinos, de 4 gêneros; ao passo que não ocorrera nenhuma morte de catarrinos pela mesma causa nesse mesmo período.

Em nossas experiências, o fato da resistência do $M$. mulatta não ter sido rompida pelos corticosteróides, corrobora em favor da idéia de que ela não é devida a um estado premunitório.

* O n. ${ }^{\circ}$ exato de rhesus não pôde ser levantado. 
Por outro lado, cabe aqui considerar como a transmissão natural deve obedecer a condições especiais. Infecções naturais em catarrinos nos últimos 60 anos, foram observadas em Cynocephalus babuin (Papio cynocephalus) por Levaditi \& Schoen (1933), em M. tantala (Lévine, 1961), em M. irus (Pokorny \& al, 1961) e em M. mulatta (Nery-Guimarães \& al, 1970), além da observação única em Hominoidea (Pan troglodytes) por Kopciowska \& Nicolau (1938). Òbviamente, êsses animais não devem ter recebido, ao se infectarem, as doses maciças que falharam na maioria absoluta das experiências.

Observa-se, portanto, que, nos primatas não humanos, há uma grande resistência dos catarrinos ao Toxoplasma, resistência que parece se atenuar nos platirrinos superiores e desaparece nos platirrinos inferiores e nos Prosimii.

A resistência dos catarrinos à toxoplasmose experimental levantou o problema de saber o seu comportamento em face do Toxoplasma em seu ambiente natural. Remington \& al (1965) submeteram à RSF catarrinos recém-chegados da Ásia, encontrando reação negativa em 64 M. mulatta e reações negativas ou insignificativas $(1: 2$ e $1: 8)$ em 50 M. nemestrina. Aliás, observações semelhantes já tinham sido feitas por Feldman \& Miller (1956). Esstes autores verificaram reações do corante negativas em 15 rhesus e negativas ou insignificativas (1:4) em 21 cinomolgus ( $M$. irus). Prabash \& al (1970) referem o encontro de 20,8\% de reações de hemaglutinação positivas em 77 macacos examinados na Índia. Vimos apenas o resumo do trabalho e não são referidos os títulos, os quais devem ter sido muito baixos.

Essa ausência de anticorpos, impôs a conclusão de que em seu meio natural os catarrinos não são expostos ao Toxoplasma. Então. como argumentam McKissick \& al (1968) a resistência dos catarrinos à toxoplasmose, não é explicada pela presença de anticorpos adquiridos.

Nossos resultados negativos da RSF, com uma única exceção (1:16), em 54 exemplares de 8 espécies de platirrinos estão de acôrdo com as observações de Werner \& al (1969) que encontraram RSF negativos em 100 Saguinus (O.) oedipus recentemente enviados da Sul-América. Estas verificações mostram que também os platirrinos não são expostos ao Toxoplasma em seu meio natural. Todavia, Werner \& al (1969) também encontraram RSF negativa em 28 Saguinus, antes e depois de infecções induzidas fatais. Se isto é freqüente em platirrinos inferiores, isto é, se êstes animais não respondem imunològicamente ao antígeno toxoplásmico, fica prejudicada tôda tentativa de demonstrar infecções latentes pela sorologia, i.e., pela RSF. 
Mem. Inst. Oswaldo Cruz, 69 (2), 1971

\section{RESUMO E CONCLUSÃO}

Após uma revisão da toxoplasmose experimental em primatas não humanos, são relatadas as tentativas, sem êxito, para provocar toxoplasmose aguda e fatal em dois rhesus (Macacca mulatta), um infante e outro jovem, por inoculação e reinoculação de uma amostra humana, usando diferentes vias e doses maciças e ainda com a ministração de decametasona. Do mesmo modo, não teve sucesso a tentativa para induzir a doença fatal em um Cebus apella adulto, pela via peritoneal. Porém a toxoplasmose-infecção nesses 3 animais, foi comprovada pela elevação da temperatura $\left(39\right.$ a $\left.41^{\circ} \mathrm{C}\right)$, pela positividade da reação de Sabin-Feldman (1:64-1:256) e pelo isolamento de toxoplasmas em camundongos inoculados com material do Cebus. Por outro lado, em um Callitbrix jacchus pela inoculação peritoneal, foi provocada doença grave e fatal com focos necróticos e abundância de toxoplasmas no baço e fígado, e isolamento dos parasitas em camundongo.

De 54 símios do Nôvo Mundo, submetidos a RSF, todos foram negativos, com exceção de um Saimiri que se mostrou positivo a 1:16 $(1,8 \%)$.

Uma análise do problema Toxoplasmose-Primatas não humanos, com apoio na revisão da literatura e nas nossas próprias observações (ver também o trabalho anterior) permite as seguintes conclusões:

a) em seu habitat natural os primatas não humanos não são expostos ao Toxoplasma. Isso deve estar relacionado aos hábitos arborícolas e à sua alimentação vegetariana e insetívora;

b) os casos descritos de toxoplasmose natural nos símios se referem a animais de cativeiro; e, mesmo nestas condições, é excepcional a infecção espontânea dos catarrinos;

c) os catarrinos apresentam, além disso uma grande resistência à indução da toxoplasmose experimental, a qual não é devida à presença de anticorpos circulantes. Essa resistência parece não ser rompida pela administração de corticosteróides; embora às vêzes o seja pela inoculação de doses maciças de toxoplasmas, e geralmente nos animais jovens;

d) essa resistência é menor nos platirrinos e parece não existir nos platirrinos inferiores e nos Prosimii. 


\section{RESUMÉ et CONCLUSIONS}

À la suite d'une revision de la toxoplasmose expérimentale chez les primates non humains on décrit les tentatives, sans succès, pour provoquer une maladie aigüe et fatale en deux rhesus (Macacca mulatta) l'un petit et l'autre jeune, par inoculation e réinoculation d'une souche humaine, utilisant des voies diverses et des doses massives ainsi que l'administration de decamétasone.

De même, la tentative de mener à une maladie fatale un Cebus apella adulte por voie du péritoine n'eut aucume succès. Cependant la toxoplasmose-infection chez ces 3 animaux fut confirmée par l'elevation de la temperature $\left(39\right.$ a $\left.40^{\circ} \mathrm{C}\right)$ par la positivité de la reaction du Sabin-Feldman (RSF) (1:64 et 1:256) et par l'isolement de toxoplasmes chez les souris inoculés avec le material du Cebus.

Par contre chez un Callitbrix jaccbus une grave et fatale maladie a été provoquée, par l'inoculation péritoneale, avec des foyers necrotiques et d'abondants toxoplasmes dans la rate et le foie.

Des 54 singes du Nouveau Monde, soumís au RSF, tous ont été négatifs sauf un Saimiri sciureus qui s'est montré positif a 1:16 (1,8\%).

Une analyse du problème Toxoplasme-Primates non humainsi scutenue par une revision de la litterature et de nos propres observations (consulter aussi le travail antérieur) permet les conclusions suivantes :

a) dans leur habitat naturel les primates non humains ne sont pas exposés au Toxoplasme, et cela se doit sans doute aux habitudes arboricoles ainsi qu'à leur alimentation végétarienne et insectivore;

b) les cas décrits de toxoplasmose naturel chez les singes se rapportant aux animaux en captivité et même dans ces conditions-là l'infection spontanée chez les catharrins est exceptionelle;

c) les catharrins présentent de plus une grande résistance à l'induction de la toxoplasmose expérimentale. Cette résistance ne parait pas être rompue par l'administration de corticosteroides malgré qu'elle le soit parfois par l'inoculation de doses massives de toxoplasmes généralement sur de jeunes animaux;

d) cette résistance est moins grande chez les plathirrins et semble ne pas exister parmis les plathirrins inférieurs et les Prosimii. 
Mem. Inst. Oswaldo Cruz, 69 (2), 1971

\section{SUMMARY AND CONCLUSIONS}

After a review of the experimental toxoplasmosis in non human primates we have reported our unsuccessful tentatives to provoke acute and fatal disease in 2 Macacca mulatta, an infant male and an young female, by inoculation and reinoculation of a human strain from congenital toxoplasmosis, using several routes and massive dosis and with the ministration of corticosteroids. We did not succeed in inducing fatal disease in an adult female Cebus apella by peritoneal and subcutaneous routes. However, the toxoplasmosis infection in these 3 monkeys was comproved by fever $\left(39\right.$ to $\left.41{ }^{\circ} \mathrm{C}\right)$, by the positivity of the Sabin-Feldman reaction $(1: 64$ and $1: 256)$ and by the isolation of the toxoplasmes from mice inoculated with material of the Cehus. On the other hand, in a Callitbrix jacchus by peritoneal route, we have provoked severe and fatal disease with necrotic foci in the lever and spleen both plenty of parasites, and isolation of toxoplasmes from mice inoculated with material of this monkey.

From 54 New World monkeys submeted to the dye test, with the exception of a Saimiri sciureus that reacted at 1:16 title, all of them were negative.

An analysis of the problem toxoplasmosis-non buman primates, based in the bibliography and in our observations (see the anterior paper too) agree with the following conclusions:

a) in its natural habitat the non human primates are not exposed to Toxoplasma infection. This fact must be related to its arboreal habits and vegetarian and insectivorous feeding;

b) the described cases of spontaneous toxoplasmosis in monkeys are related to animals in cages; and at this very condition the natural infection of the catharrhinus monkeys is exceptional;

c) besides, the catharrhinus monkeys presented a great resistence to the experimental toxoplasmosis and these resistence is not due to circulating antibodies. These resistence seems to be not broken by the ministration of corticosteroids. However these resistence is broken sometimes by massive dosis of parasites and generally in the young animals;

d) these resistence is smaller in the platyrrhinus monkeys and it seems to be absent in the inferior platyrrhinus and in the Prosimii. 


\section{ZUSAMMENFASSUNG}

Nach einer experimentellen Toxoplasmose bei nicht menschlichen Primaten, werden in dieser Arbeit die misslungenden Versuche beschrieben eine akute und fatale Toxoplasmose hervorzubringen an zwei jungen Rhesusaffen (Macacca mulatta). Es wurden mehrere Inokulationen mit einem Stamm von menschlicher Herkunft gemacht, wofür verschiedene Verabreichugsarten und grosse Dosen benutzt wurden. Hierzu wurde auch noch decametasona verabreicht. Ebenfalls scheiterte der Versuch eine fatale Krankheit hervorzurufen an einem erwachsenen Cebus apella durch intraperitonealer Injektion Die Infektion konnte aber bei diesen 3 Tieren nachgewiesen werden: a) Durch die Temperatur erhöung (39 bis 41). b) Durch die Positivität der SabinFeldman Reaktion (1:64-1:256). c) Durch die Isolierung von Toxoplasmen aus Mäusen die man mit Material vom Cebus inokulierte.

Anderseits gelang es an einem Callitbrix jaccbus durch intraperitonealer Inokulation eine ernsthafte Krankheit zu provozieren, mit nekrotischen foci und grosse Mengen Toxoplasmen in der Milz und in der Leber. Weiter konnte man nach Übertragung auf Mäuse, die Parasiten isolieren. Von 54 Affen der Neuen Welt, die auf der SabinFeldman Reaktion untersucht wurden, ergaben alle negativ mit Ausnahme eines Saimiri Affen, der positiv anzeigte mit 1:16 (1,8\%).

Auf Grund der nachgeforschten Literatur und unseren eigenen Beobachtungen, dürfen wir, was eine Analyse der Toxoplasmose bei nicht menschlichen Primaten Problematik anbelangt, die folgenden Folgerungen ziehen:

a) in ihren natürlichen Habitat sind die nicht menschlichen Primaten den Toxoplasmen nicht ausgesetzt. Dies soll irgendwie zusammen hängen mit ihrer Nahrung, die hauptsächlich aus Pflanzen und Insekten besteht, und mit ihren Lebensgewohnheiten;

b) die beschriebenen Fälle von Spontaner Toxoplasmose in Affen beziehen sich auf Tiere in Gefangenschaft; und selbst in diesen Umständen ist die spontane Infektion der Catbarrbynus eine Ausnahme;

c) ausserdem zeigen die Catharrbynus eine grosse Resistenz gegen die Induktion der experimentellen Toxoplasmose. Diese Resistenz ist nicht die Anwesendheitvon Antikörpern zuzuschreiben. Anscheinend wird sie nicht gebrochen durch die Verabreichung von Corticosteroides, obwohl dies passieren kann durch Inokulierung von grossen Dosen Toxoplasmen und dennoch bei jüngeren Tieren;

d) diese Resistenz zeigt sich geringer bei den Platyrrbynus und ist anscheinend nicht anwesen bei den niedrigen Platyrrbinus und bei den Prosimii. 
Agradecimentos: Ao Dr. Miguel Azevedo, Diretor do Instituto Evandro Chagas, pelos sôros de 40 símios da Amazônia; e ao Dr. Walmir Oliveira de Almeida, Diretor do Jardim Zoológico da Guanabara, pela permissão para sangria de 14 símios ainda não exibidos.

\section{REFERÊNCIAS BIBLIOGRAFICAS}

BLAND, J. (1931) - Glandular Fever II - The protozoal nature of the experimental disease. Brit. J. Exp. Path 45: 311.

Cowen, D. \& Wolf, A. (1945) - Toxoplasmosis in the monkey acute fatal infection experimentally produced in a young Macacca mulatta. J. Infect. Dis. 77: 144.

Feldman, H. A. \& Miller, L. T. (1956) - Serological Study of Toxoplasmosis prevalence. Amer. J. Hyg. 64: 320.

FrenkeL \& JACOBS, L. (1958) - Ocular toxoplasmosis: Pathogenesis, diagnosis and treatment. Arch. Ophtalm. 59: 260.

Kopciowska, L. \& Nicolau, S. (1938) - Toxoplasmose expontanée du chimpanzé. C.R. SoC. Biol., 128: 179.

Levaditi, C., Sanchis-Bayarri, V. LìPine, P. \& Schoen R. (1929) - Étude sur l'encephalomyèlite provoquée par Toxoplasma cuniculi. Ann. Inst. Pasteur. 43: 673.

Levaditi, C. \& Schoen, R. (1933) - Présence d'un toxoplasmose dans l'encephale de Cynocephalus babuin. Bull. Soc. Path. exot. 26: 402.

Levine, N. D. (1961) - Prótozoan Parasites of Domestic animals and of Man. Pp. 58 and 325. Burgess Publishing Co. Mineapolis, 1961.

Makstentecks, O. \& VerLinde, J. D. (1957) - Toxoplasmosis in the Netherlands. Clinical interpretation of parasitological examinations and epidemiological relationships between toxoplasmosis in man and animals. Docum. Med. Geog. Trop., 9: 213.

Mc. Kissick, G. E., Ratcliffe, H. L. \& KoestneR, A. (1968) Enzootic Toxoplasmosis in caged Squirrel Monkeys Saimiri sciureus. Path. Vet. Intern. J. Vet. Path. 5 (6): 538.

Mohr, W., Wahle, H., \& STAmmler, A. (1955) - Experimentelle Toxoplasmose Infektion beim Rhesusaffen Z. Tropenmed. Parasit. 6: 386.

Nery-Guimarães, F., Franken, J. A. \& Chagas, W. A. - Toxoplasmose em primatas não humanos I - Infecções naturais em Macacca mulatta e Cebus apella. Ver mesmo número desta revista.

NrColle, C. \& Conor, M. (1913) - La toxoplasmose du gondii: Maladie naturalle. Maladie experimentale. Bull. Soc. Path. Exot. 6: 160.

Nicolle, C. \& MANCeAU, L. (1909) - Sur un protozoaire nouveau du gondi. "Comte Rendu" Ac. Sc., 148: 369.

POKORNY, J. HunNer, J. \& ZÀstera, M. (1961) - Toxoplasma gondii z nekterych domécich i volne zijicich zuirat (Isolamento de Toxoplasma de certos animais domésticos e de vida livre na Checoslováquia). Resumo em inglês. Cs. Epidem., 10: 323. 
Prabash, O., Chowdnry, P. \& Gill, H. S. (1970) - Epidemiology of Toxoplasmosis in India "Parasitology", 56: 272 2nd Inter. Cong. Parasitology, Part I.

Remington, J. S., Soave, O. A. \& Davis, J. (1965) - "A serological survey in three species of monkeys". Amer. J. trop. Med. Hyg. 14: 724.

RHodANICHE, E., (1954) - Susceptibility of the marmoset Marikina geoffroyi and the night monkey Aotus zonalis to experimental infection with Toxoplasma. Amer. J. trop. Med. Hyg. 3: 1026.

RUCh, T. G. (1959) - Diseases of Laboratory Primates, Pp 297, 313, 423, W. B. Saunders Co., Philadelphia/London.

SABIN, A. B. (1941) - Toxoplasmic Encephalitis in Children. J. Amer. Med. Ass. 116: 801.

Sabin, A. B. \& Feldman, H. (1948) - "Dyes as microchemical indicators of as new immunity phenomenon affecting a protozoan parasite". Science, 108: 660.

SAbin, A. B. \& Olitsky, P. K. (1937) - Toxoplasma and Obligate Intracellular Parasitism. Science, 85: 336.

Sabin, A. B. \& Ruchman, J. (1942) - Characteristics of the Toxoplasma Neutralizing Antibodie. Proc. Exp. Biol. Med. 51: 1.

Sureau, P., Raynaud, J. P., Lapeire, C. \& Brygoo, E. R. (1962) - Premier isolement de Toxoplasma gondii à Madagascar. Toxoplasmose spontanée et experimentale de Lemur catta. Bull. Soc. Path. Exot. 55: 357.

Weinman, D. \& ANNE H. Chandier (1956) - Toxoplasmosis in man and swine. An. investigation of the possible relationship. J. A. M. A., 161: 229.

WeRneR, H., JANITSCHKe, K. \& KöHLER, H. (1968) - Über Beobachtungen an Marmoset - Affen Saguinus (Oedipomidas) oedipus nach oraler und intraperitonealer Infektion mit verschiedenen systenbildenden Toxoplasma - Stämmen unterschiedlicher Virulenz Zbl, Bakt, I. Abt. Orig 209: 553.

Wolf, A., Cowen, D. \& PaIge, B. (1940) - Toxoplasmic Encephalomyelitis. IV Experimental transmission of the infection to animal from a human infant. J. Exp. Med. 71: 187. 


\section{ESTAMPA I}

Toxoplasmose experimental em Callithrix jacchus. Cortes de fígado. a) Foco necrótico. $140 \mathrm{X}$. b) Toxoplasmas nos sinusoides. c) Pseudocisto na cápsula de Glisson. d) Macrófagos com parasitos nos espaços-porta. $1.400 \mathrm{X}$. Hematoxilina-eosina. 

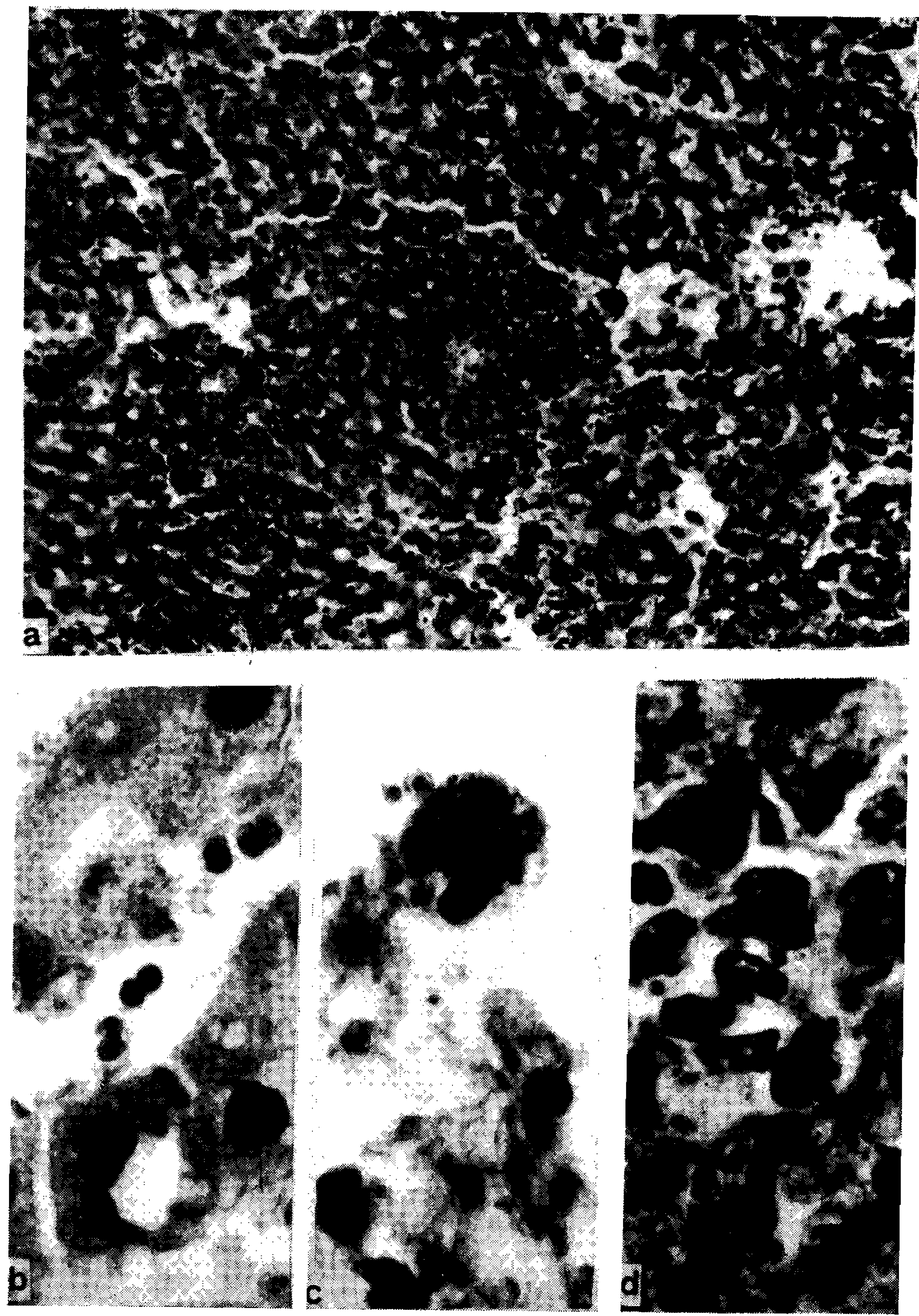

Nery-Guimarães \& Franken: Toxoplasmose em primatas II 
ESTAMPA II

Toxoplasmose experimental em Callithrix jacchus. Baço. a) Áreas necróticas. 140 X. $b, c$ e $d$ ) Toxoplasmas isolados, livres e intracelulares, em pequenos grupos e sob a forma de pseudocisto. $1.400 \mathrm{X}$. Hematoxilina-eosina. 

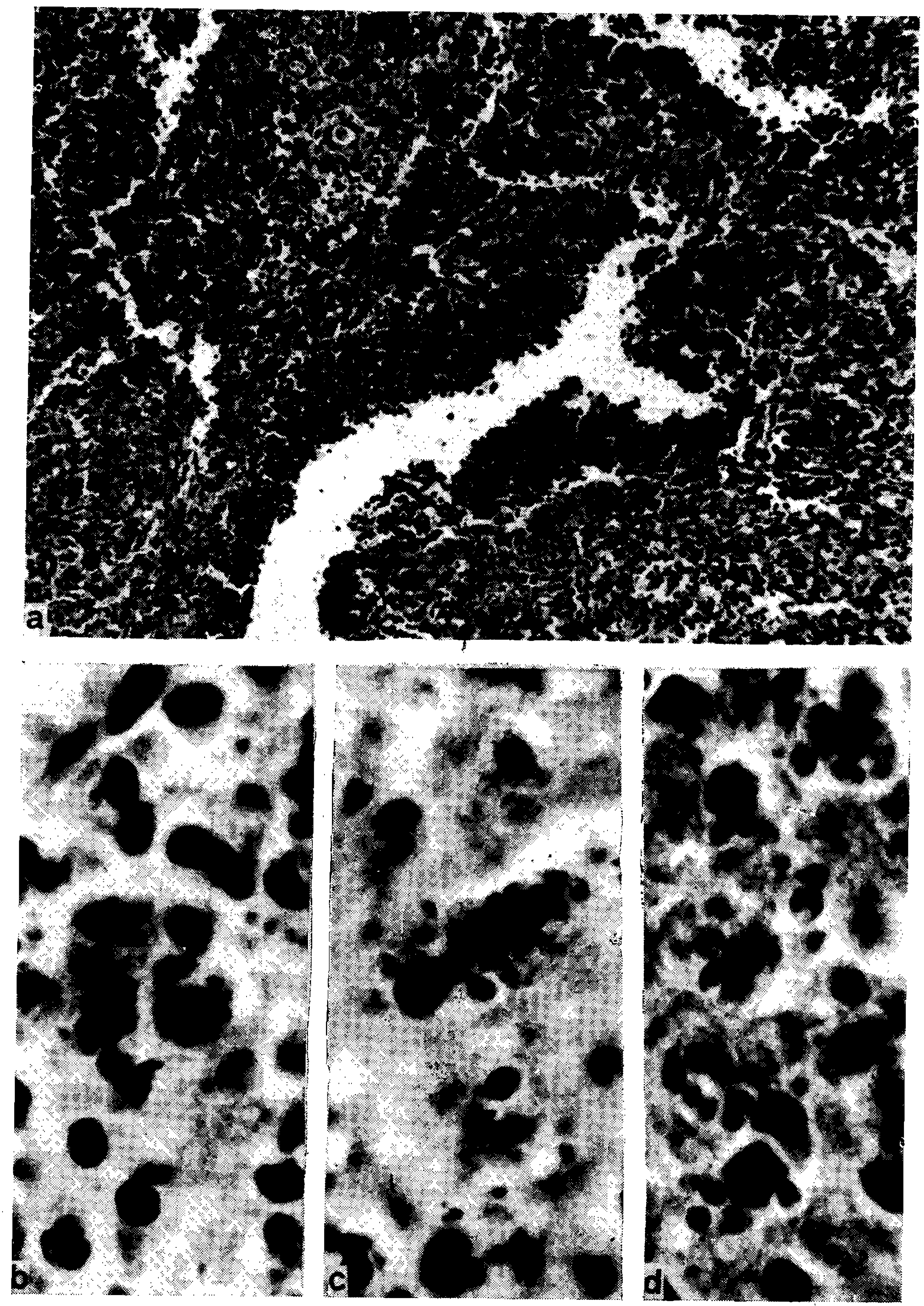

Nery-Guimarães \& Franken: Toxoplasmose em primatas II 
ESTAMPA III

Toxoplasmose experimental em Macacca mulatta. a) Fígado. Foco inflamatório de células redondas em um espaço-porta. $140 \mathrm{X}$. b) Coração Foco de miocardite com relacionamento vascular. $140 \mathrm{X}$. Não foram vistos toxoplasmas nessas lesões. Hematoxilina-eosina. 

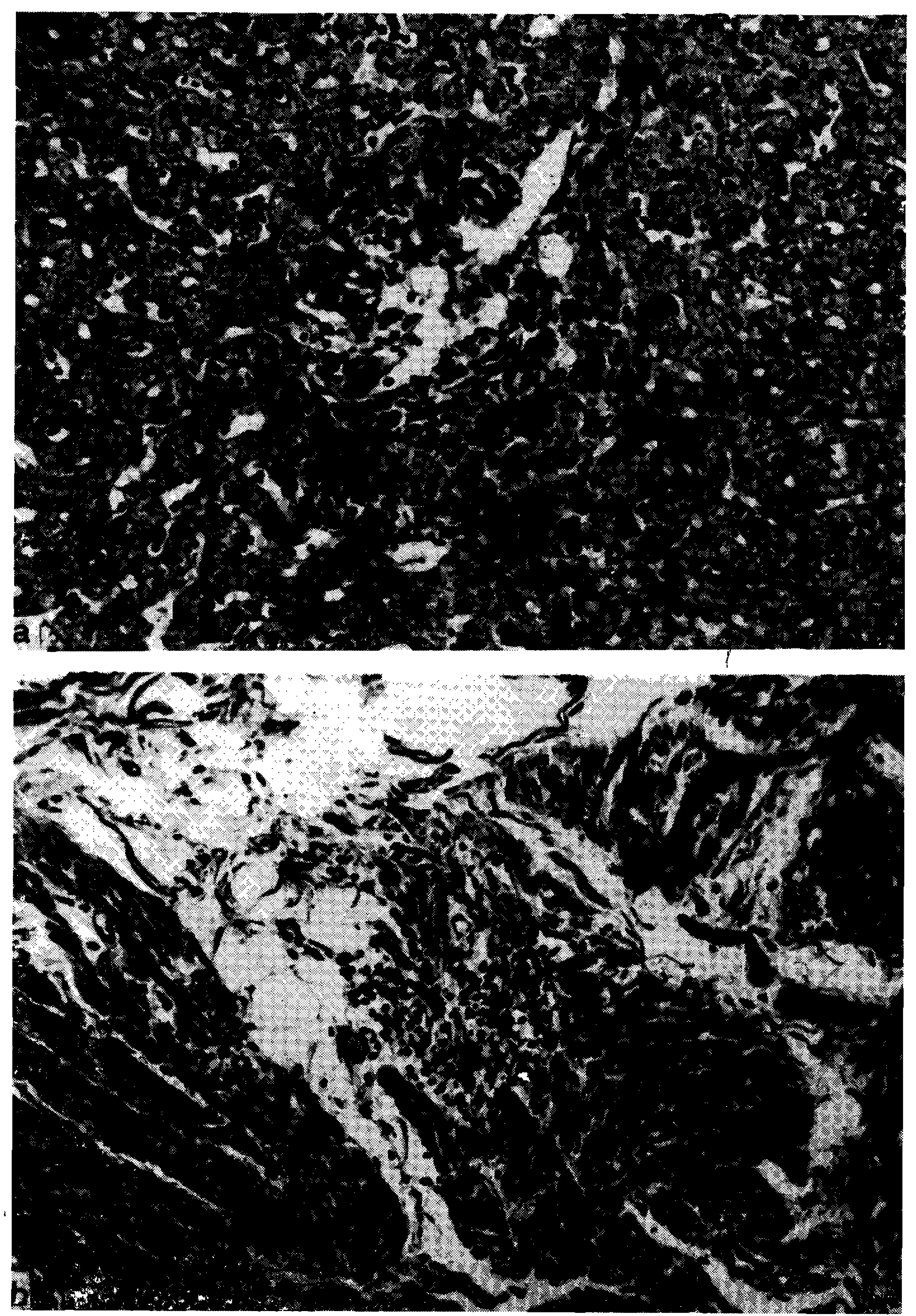

Nery-Guimarães \& Franken: Toxoplasmose em primatas II 


\section{ESTAMPA IV}

Toxoplasmose experimental em Cebus apella. a) Acúmulos de células redondas no fígado. $560 \mathrm{X}$. b) Presença de macrófagos nas paredes alveolares. $560 \mathrm{X}$. No pulmão como no fígado, não foram vistos toxoplasmas. Hemotoxilina-eosina. 
$69(2): 97-111-1971$

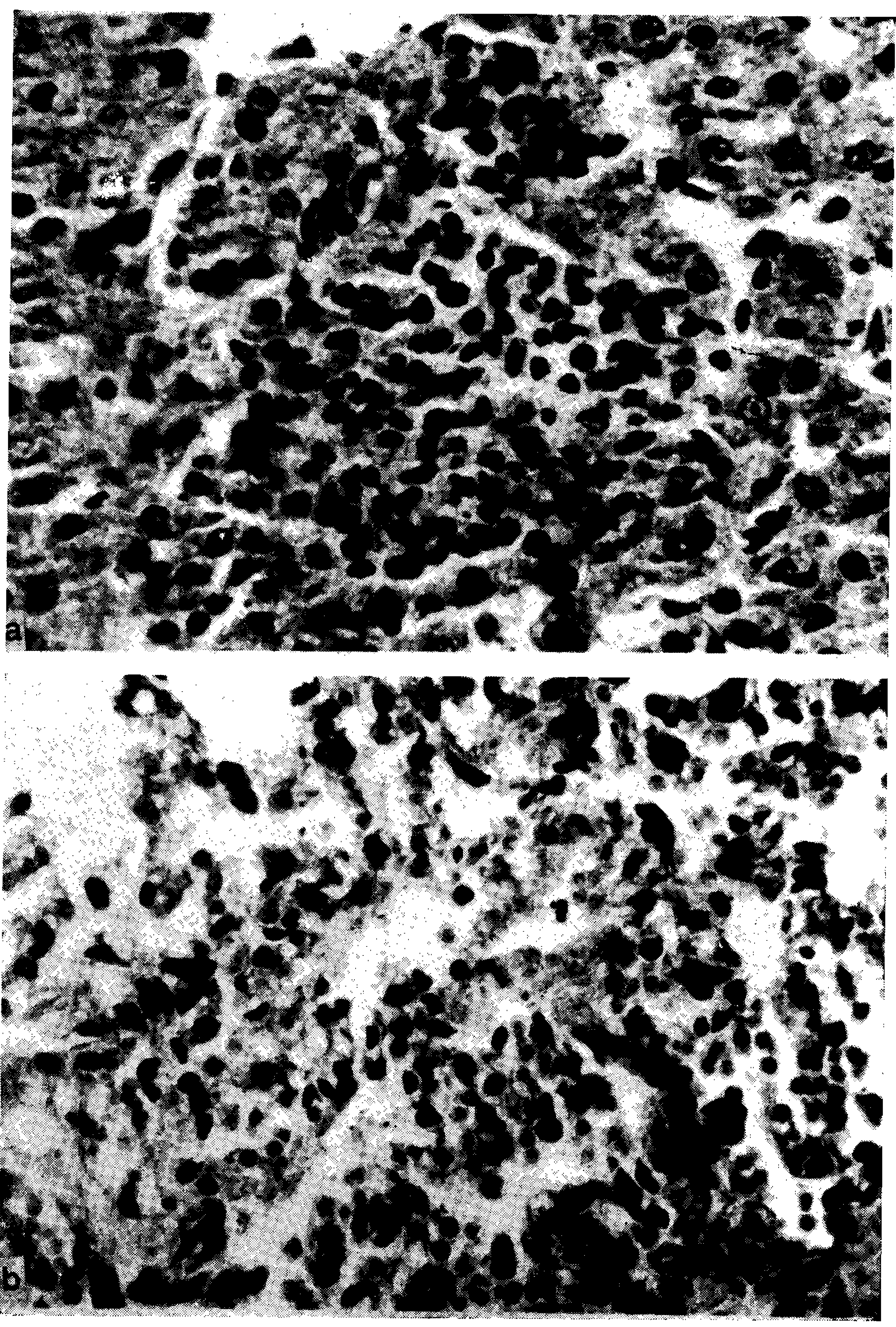

Nery-Guimarães \& Franken: Toxoplasmose em primatas II 